\title{
Bio-guided isolation of anti-leishmanial natural products from Diospyros gracilescens L. (Ebenaceae)
}

Cyrille Armel N. Njanpa', Steven Collins N. Wouamba², Lauve Rachel T. Yamthe ${ }^{1,3}$, Darline Dize ${ }^{1}$, Brice Mariscal T. Tchatat ${ }^{1}$, Patrick Valère F. Tsouh ${ }^{4}$, Michel Nguiam Pouofo ${ }^{5}$, Jean Bosco Jouda ${ }^{7}$, Bruno Lenta Ndjakou ${ }^{2}$, Norbert Sewald ${ }^{6}$, Simeon Fogue Kouam ${ }^{2^{*}}$ and Fabrice Fekam Boyom ${ }^{1^{*}}$

\begin{abstract}
Background: Plants represent an intricate and innovative source for the discovery of novel therapeutic remedies for the management of infectious diseases. The current study aimed at discovering new inhibitors of Leishmania spp., using anti-leishmanial activity-guided investigation approach of extracts from Diospyros gracilescens Gürke (1911) (Ebenaceae), targeting the extracellular (promastigotes) and intracellular (amastigotes) forms of Leishmania donovani.

Methods: The plant extracts were prepared by maceration using $\mathrm{H}_{2} \mathrm{O}$ : EtOH $(30: 70, \mathrm{v} / \mathrm{v})$ and further fractionated using a bio-guided approach. Different concentrations of $D$. gracilescens extracts, fractions and isolated compounds were tested in triplicate against $L$. donovani promastigotes and amastigotes in vitro. The antileishmanial potency and cytotoxicity on RAW 264.7 cells were determined using the resazurin colorimetric assay. The time kill kinetic profile of the most active sample was also investigated. The structures of all compounds were elucidated on the basis of extensive spectroscopic analyses, including 1D and 2D NMR, and HR-ESI-MS and by comparison of their data with those reported in the literature.

(Continued on next page)
\end{abstract}

\footnotetext{
* Correspondence: kfogue@yahoo.com; fabrice.boyom@fulbrightmail.org

${ }^{2}$ Department of Chemistry, Higher Teacher Training College, University of

Yaounde I, P. O. Box 47, Yaounde, Cameroon

${ }^{1}$ Antimicrobial and Biocontrol Agents Unit, Laboratory for Phytobiochemistry and Medicinal Plants Studies, Department of Biochemistry, Faculty of science University of Yaounde I, P. O Box 812, Yaounde, Cameroon

Full list of author information is available at the end of the article
}

C C The Author(s). 2021 Open Access This article is licensed under a Creative Commons Attribution 4.0 International License, which permits use, sharing, adaptation, distribution and reproduction in any medium or format, as long as you give appropriate credit to the original author(s) and the source, provide a link to the Creative Commons licence, and indicate if changes were made. The images or other third party material in this article are included in the article's Creative Commons licence, unless indicated otherwise in a credit line to the material. If material is not included in the article's Creative Commons licence and your intended use is not permitted by statutory regulation or exceeds the permitted use, you will need to obtain permission directly from the copyright holder. To view a copy of this licence, visit http://creativecommons.org/licenses/by/4.0/. The Creative Commons Public Domain Dedication waiver (http://creativecommons.org/publicdomain/zero/1.0/) applies to the data made available in this article, unless otherwise stated in a credit line to the data. 
(Continued from previous page)

Results: The hydroethanolic crude extract of $D$. gracilescens trunk showed the most potent antileishmanial activity $\left(I C_{50}=5.84 \mu \mathrm{g} / \mathrm{mL}\right)$. Further fractionation of this extract led to four (4) fractions of which, the hexane fraction showed the most potent activity $\left(\mathrm{IC}_{50}=0.79 \mu \mathrm{g} / \mathrm{mL}\right)$, and seven $(07)$ compounds that exhibited moderate potency $\left(\mathrm{IC}_{50}=13.69-241.71 \mu \mathrm{M}\right)$ against $L$. donovani. Compound 1-deoxyinositol (7) inhibited the promastigote and amastigote forms of $L$. donovani with $\mathrm{IC}_{50}$ values of $241.71 \mu \mathrm{M}$ and $120 \mu \mathrm{M}$ respectively and also showed the highest selectivity against L. donovani promastigotes (SI > 5.04). To the best of our knowledge, the antileishmanial activity of this compound is being reported here for the first time. The promising hexane fraction showed significant inhibition of parasites growth at different concentrations, but with no evidence of cidal effect over an exposure period of $120 \mathrm{~h}$.

Conclusions: The results obtained indicated that the hydroethanolic extract from the D. gracilescens trunk and the derived hexane fraction have very potent inhibitory effect on cultivated promastigotes and amastigotes of $L$. donovani parasite. The isolated compounds showed a lesser extent of potency and selectivity. However, further structure-activity-relationship studies of 1-deoxyinositol could lead to more potent and selective hit derivatives of interest for detailed drug discovery program against visceral leishmaniasis.

Keywords: Diospyros gracilescens, Ebenaceae, Hexane fraction, Isolated compounds, Antileishmanial, Cytotoxicity, 1deoxyinositol

\section{Background}

Leishmaniasis is a severe, widespread zoonotic and parasitic disease caused by an intracellular flagellate protozoan of the genus Leishmania. The disease is generally transmitted between man and animals during a blood meal by the phlebotome female sandfly. About 20 different Leishmania species including $L$. donovani have been discovered to be pathogenic to human. The clinical features of the disease include a wide range of manifestations, including skin ulcers at the site of the infection or dissemination in visceral organs followed by anemia, leucopenia, fever and weakness $[1,2]$. The World Health Organization estimates that 1.3 million new cases of leishmaniasis occur every year with 20,000 to 30,000 deaths annually [3]. Therefore, a great concern has been expressed by the WHO, as leishmaniases are considered as neglected tropical diseases [4]. Visceral leishmaniasis (VL), caused by L. donovani is the most dangerous form of the disease that can be lethal in human when untreated. It is considered as a serious public health problem worldwide, and especially in Africa where its significant morbidity and mortality require more effective chemotherapy [5]. Current available chemotherapy includes the first line treatment drugs such as pentavalent antimonials, meglumine antimoniate (glucantime) and sodium stibogluconate (pentostam) and second line drugs such as amphotericin B, pentamidine, paromomycin and miltefosine $[6,7]$. However, these drugs are limited by factors such as emergence of drug resistance, especially with the pentavalent antimonials and challenges of toxicity, short half-life and high cost of drugs, as well as failure of patient to comply with treatment [8, 9]. Due to the limitations of current chemotherapeutic regimes and in the absence of effective and sustainable vaccines, there is a persistent need for alternative and readily available sources for treatment of leishmaniasis. In this respect, natural products offer good sources for new drug discovery [10].

This paper describes the in vitro antileishmanial activity of natural products from $D$. gracilescens, a plant of Ebenaceae family. It is a forest tree widely distributed in West and Centre regions of Cameroon. Furthermore, there is no mention of use of D. gracilescens in traditional medicine in Cameroon. However, related species such as D. bipindensis (Gürke), D. conocarpa (Gürke \& K. Schum.) and D. malabarica ((Descr.) Kostel.) are widely used by Baka Pygmies for the treatment of malaria, sleeping sickness and respiratory disorders [11]. Globally, Diospyros spp. are known above all, as fishing poisons, especially in South East Asia and in the Philippines. They are also widely-used medications in traditional African medicine, mainly against leprosy. The roots are used as purgative in the Central African Republic, against pneumonia in Zimbabwe and schistosomiasis in Malawi $[12,13]$. The first chemical study of $D$. gracilescens led to the isolation of few compounds such as: lupeol, betulin, betulinic acid, isodiospyrin (II) and sitosterol [14]. Of note, this is the first report of antileishmanial guided isolation of the chemical constituents of D. gracilescens.

\section{Methods \\ Phytochemical investigation of D. gracilescens Collection of plant material and preparation of the crude extracts}

The plant materials (root, trunk, stem bark and leaf) of D. gracilescens, were collected in March 2017 at Eloumdem mountain (GPS coordinates: Latitude $3^{\circ} 49^{\prime} 00^{\prime \prime} \mathrm{N}$, 
Longitude $11^{\circ} 25^{\prime} 60^{\prime \prime} \mathrm{E}$ ), in the Centre Region of Cameroon and were identified by comparison with a voucher specimen (No. 2016 / SRFK) from the National Herbarium of Cameroon by Mr. Victor Nana, a botanist.

The collected plant materials were dried under shelter at room temperature and further ground to obtain the powders. The tinctures were prepared by maceration of $4000 \mathrm{~g}$ of each powder in aqueous ethanol 70\% (15 L, 48 $h \times 3)$. The resulting macerates were filtered using Whatman filter paper No. 2 and the filtrates concentrated on a Büchi rotary evaporator (Büchi Labortechnik AG - Flawil, Switzerland) under reduced pressure at 45$55^{\circ} \mathrm{C}$ and further lyophilized using a freeze-dryer Alpha 2-4 LD plus (Christ, Germany) to yield the crude extracts. Each extract was kept dried in tightly stoppered bottles at $4{ }^{\circ} \mathrm{C}$ until it was used for the biological screenings.

\section{Liquid-liquid partition of the trunk crude extract}

The crude extract of the trunk (150 g) which showed the best leishmanicidal activity was fractionated by liquidliquid partition as shown in Fig. 1, according to the procedure described by Xie et al. [15]. Briefly, $140 \mathrm{~g}$ of the crude extract was suspended in water and then extracted with $\mathrm{n}$-hexane, dichloromethane, ethyl acetate and $n$-butanol successively (Fig. 1). Each fraction was evaporated under reduced pressure at $45-55^{\circ} \mathrm{C}$ and then the aqueous fraction was lyophilized. Five residues were obtained and respectively named fraction A from $n$-hexane [ $6.5 \mathrm{~g}$,

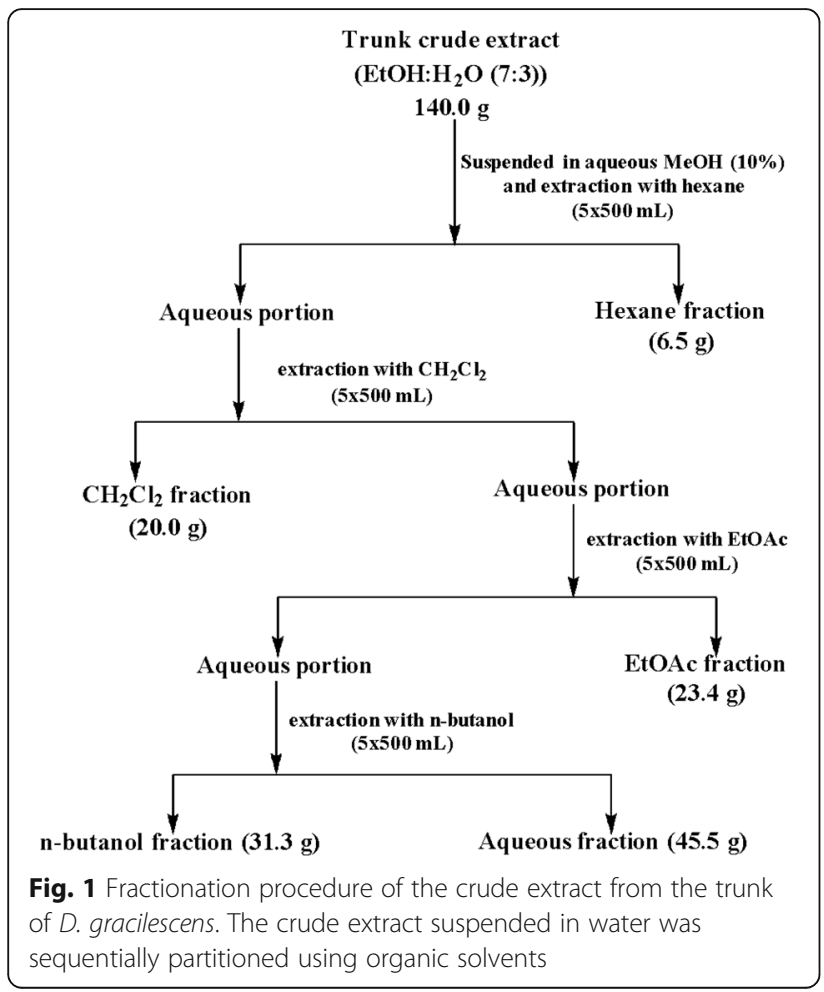

4.6\% yield], fraction B from dichloromethane [20.0 g, $14.3 \%$ yield], fraction $C$ from ethyl acetate [23.4 g, $16.7 \%$ yield], fraction D from $n$-butanol [31.3 g, 22.35\% yield] and fraction $\mathrm{E}$ for the remaining aqueous residue ( $45.5 \mathrm{~g}$, $32.50 \%$ yield). Each of the afforded fractions was submitted to antileishmanial screening and the promising ones (fractions $\mathrm{A}, \mathrm{B}$ and $\mathrm{D}$ ) having $\mathrm{IC}_{50}$ values below $2 \mu \mathrm{g} / \mathrm{mL}$ were selected and submitted to chromatographic separation.

\section{Chromatography of the active fractions}

Chromatography of fraction A A portion of $n$-hexane fraction $\left(\mathrm{m}=6 \mathrm{~g} ; \mathrm{IC}_{50}=0.78 \mu \mathrm{g} / \mathrm{mL}\right)$ was subjected to silica gel column chromatography eluting with an isocratic system of $n$-hexane/ethyl acetate (95/5). Three hundred sub-fractions of ca $100 \mathrm{~mL}$ each were collected and combined into 10 sub-fractions A1-A10 based on their TLC profiles. Sub-fractions A1 to A6 consisted of a mixture of fatty acids and were not investigated further. Lupeol (1) (1.11 mg) and a mixture of $\beta$-sitosterol (4) and stigmasterol (5) (14.8 mg) were obtained from subfractions A7-8 (n-hexane/EtOAc (95/5), $1.5 \mathrm{~g}$ ) and subfractions A9\&10 ( $n$-hexane/EtOAc 90/10, $2.2 \mathrm{~g}$ and 80/ $20,22 \mathrm{mg}$ ) respectively $[16,17]$.

Chromatography of fraction B The dichloromethane fraction ( $\mathrm{m}=19 \mathrm{~g} ; \mathrm{IC}_{50}=1.63 \mu \mathrm{g} / \mathrm{mL}$ ) was subjected to column chromatography on 230-400 mesh silica gel (Merck, Darmstadt, Germany) eluting with a gradient of ethyl acetate in $n$-hexane. Ninety sub-fractions of ca 250 $\mathrm{mL}$ each were collected and combined into 4 major subfractions B1-B4 according to their TLC profiles. Subfraction B1 (n-hexane/EtOAc (95/5), $8.1 \mathrm{~g}$ ) was found to contain mainly fatty substances and traces of hexane soluble compounds. Sub-fraction B2 (n-hexane/EtOAc (90/ 10), $2.1 \mathrm{~g}$ ) was subjected to repeated silica gel column chromatography using a mixture of $n$-hexane:ethyl acetate in a gradient mode as eluent to afford the mixture of $\beta$-sitosterol (4) and stigmasterol (5) (17.6 mg). Subfraction B4 ( $n$-hexane/EtOAc (65/35), $4.5 \mathrm{~g}$ ) was fractionated on silica gel column chromatography with an isocratic solvent system of n-hexane/ethyl acetate (30/ 70) to afford a mixture of compounds 2 and 3 which were further purified using a sephadex LH-20 (SigmaAldrich, Munich, Germany) column chromatography with a mixture of $\mathrm{CH}_{2} \mathrm{Cl}_{2} / \mathrm{MeOH}(20 / 80)$ as eluent to afford pure betulin (2) (2.0 mg) and betulinic acid (3) (27 mg) [17-19]. Sub-fraction B3 was not further studied due to limited quantity.

Chromatography of fraction $\mathbf{D}$ The n-butanol fraction $\left(\mathrm{m}=30 \mathrm{~g} ; \mathrm{IC}_{50}=1.11 \mu \mathrm{g} / \mathrm{mL}\right)$ was subjected to silica-gel column chromatography eluting with a mixture of $n$ - 
hexane/acetone/methanol in a gradient mode. Twenty sub-fractions of ca $400 \mathrm{~mL}$ each were collected and combined into 5 major sub-fractions D1-D5 based on their TLC profiles. Beta-Sitosterol glucoside (6) $(185 \mathrm{mg})$ precipitated in sub-fraction D1 (n-hexane/Acetone 30/70). Compound 1-deoxyinositol (7) (30 mg) precipitated in sub-fraction D5 (n-hexane/Acetone/Methanol (3/6/1)) and was filtered before being purified by recrystallization in acetone/water $(90 / 10)[11,20]$. Data on sub-fractions D2-3 are not presented in this paper because they are under further scrutiny.

\section{HPLC-DAD-ESI-MS analysis of extracts from $D$. gracilescens}

Sample preparation Each extract was dissolved in HPLC grade methanol at a concentration of $0.5 \mathrm{mg} / \mathrm{mL}$, then filtrated through a syringe-filter-membrane. Each aliquot obtained $(5 \mu \mathrm{L})$ was injected into the UPLCDAD-HRESI/MS Dionex Ultimate 3000 HPLC (Germany) apparatus used to perform the analyses.

HPLC-MS conditions High resolution mass spectra were obtained with an OTOF Spectrometer (Bruker, Germany) equipped with a HRESI source and a UV-vis absorbance detector. The spectrometer was operated in positive mode (mass range: 100-1500, with a scan rate of $1.00 \mathrm{~Hz}$ ) with automatic gain control to provide highaccuracy mass measurements with $2 \mathrm{ppm}$ deviation using Na Formate as calibrant. Mass spectra were simultaneously acquired using electrospray ionization in the positive ionization mode. The following parameters were used for experiments: spray voltage of $4.5 \mathrm{kV}$, capillary temperature of $200^{\circ} \mathrm{C}$. Nitrogen was used as sheath gas $(10 \mathrm{l} / \mathrm{min})$. The spectrometer was attached to an Ultimate 3000 (Thermo Fisher, USA) HPLC system consisting of LC-pump, UV traces were measured at 215, 218, 254, 280 and $330 \mathrm{~nm}$ and UV spectra-Diode Array Detector- (DAD) was recorded between 190 and $600 \mathrm{~nm}$, auto sampler (injection volume $5 \mu \mathrm{l}$ ) and column oven $\left(35^{\circ} \mathrm{C}\right)$. The separations were performed using a Synergi MAX-RP $100 \mathrm{~A}(50 \times 2 \mathrm{~mm}, 2.5 \mu$ particle size $)$ with a $\mathrm{H}_{2} \mathrm{O} \quad(+0.1 \% \quad \mathrm{HCOOH}) \quad(\mathrm{A}) /$ acetonitrile $\quad(+0.1 \%$ $\mathrm{HCOOH}$ ) (B) gradient (flow rate $500 \mu \mathrm{L} / \mathrm{min}$ ). Samples were analyzed using a gradient program as follows: $95 \%$ A isocratic for $1.5 \mathrm{~min}$, linear gradient to $100 \%$ B over 6 $\mathrm{min}$, after $100 \% \mathrm{~B}$ isocratic for $2 \mathrm{~min}$, the system returned to its initial condition $(90 \% \mathrm{~A})$ within $1 \mathrm{~min}$, and was equilibrated for $1 \mathrm{~min}$.

Identification of peaks Identification of all constituents was performed by UPLC-DAD-HRESI/MS analysis and by comparing the UV, MS spectra and MS/MS fragmentation of the selected peaks in the sample chromatogram with those of data reported the literature of SciFinder database.

\section{Screening of extracts for biological activity Parasite culture and maintenance}

The cryopreserved promastigote form of $L$. donovani (1S (MHOM/SD/62/1S) was obtained from Bei Resources (https://www.beiresources.org/) and is routinely cultured at the Antimicrobial and Biocontrol Agents Unit, University of Yaoundé I, in Medium 199 (Sigma, Darmstadt, Germany) supplemented with $10 \%$ Heat-Inactivated fetal Bovine Serum (HIFBS) (Sigma, Darmstadt, Germany) and $100 \mathrm{IU} / \mathrm{mL}$ penicillin and $100 \mu \mathrm{g} / \mathrm{mL}$ streptomycin. The culture was maintained in $75 \mathrm{Cm}^{2}$ cell culture flask at $28^{\circ} \mathrm{C}$ and checked for growth daily and sub-cultured everyday $72 \mathrm{~h}[21]$.

\section{Determination of the antileishmanial activity of plant extracts and fractions}

Inhibitory assay against $L$. donovani promastigotes The antileishmanial activity of $D$. gracilescens crude extracts, derived fractions and compounds against cultured $L$. donovani promastigotes was evaluated using the resazurin colorimetric assay as described by Siqueira-Neto et al. [22]. The stock solutions were prepared by dissolving each sample in 100\% dimethyl sulfoxide (DMSO) and subsequently diluted serially in non-supplemented culture medium. To assess the antileishmanial activity, $4 \times 10^{5}$ promastigotes $/ \mathrm{mL} /$ well were seeded in a 96 well microtiter plate and treated with 5 -fold diluted concentrations of $D$. gracilescens extracts $(0.16,0.8,4,20$ and $100 \mu \mathrm{g} / \mathrm{mL}$ ) for $72 \mathrm{~h}$ at $28^{\circ} \mathrm{C}$. The viability rate of promastigotes positively correlated with the amount of pink resorufin that was produced through the reduction of blue resazurin by the dehydrogenase enzymes in the inner mitochondrial membrane of the living parasites. Briefly, promastigotes from a logarithmic phase culture $\left(4 \times 10^{5}\right.$ cells $\left./ \mathrm{mL} ; 90 \mu \mathrm{L}\right)$ were seeded in 96 -well microtiter plates and were treated with $10 \mu \mathrm{l}$ of inhibitors at different triplicate concentrations ranging $100 \mu \mathrm{g} / \mathrm{mL}$ $0.16 \mu \mathrm{g} / \mathrm{mL}$ for extracts and fractions and $50 \mu \mathrm{g} / \mathrm{mL}-$ $0.08 \mu \mathrm{g} / \mathrm{mL}$ for compounds. The final concentration of DMSO in each well was not higher than $1 \%$. Plates were incubated for $28 \mathrm{~h}$ at $28^{\circ} \mathrm{C}$, followed by the addition of $1 \mathrm{mg} / \mathrm{mL}$ resazurin (Sigma, Darmstadt, Germany). The negative and positive controls were 0.1\% DMSO and amphotericin B (Sigma, Darmstadt, Germany) (10$0.016 \mu \mathrm{g} / \mathrm{mL}$ ) respectively. After an additional incubation for $44 \mathrm{~h}$, plates were then read on a Magelan Infinite M200 fluorescence multi-well plate reader (Tecan, Männedorf, Switzerland) at an excitation and emission wave lengths of 530 and $590 \mathrm{~nm}$ respectively. For each sample, growth percentages were calculated and dose-response 
curves were constructed to determine the $50 \%$ inhibitory concentration $\left(\mathrm{IC}_{50}\right)$ using the GraphPad Prism-version 5.0 software (San Diego, California, USA).

Inhibitory assay against $\boldsymbol{L}$. donovani amastigotes The effect of plant isolates against the intracellular amastigote form of $L$. donovani was evaluated essentially as described by Jain et al. [23] with some modifications. Briefly, macrophage Raw 264.7 cells $\left(4 \times 10^{3}\right.$ cells/well $)$ were seeded in 96 well plates and incubated for $6 \mathrm{~h}$ at $37^{\circ} \mathrm{C}$ under $5 \% \mathrm{CO}_{2}$ for adhesion of the cells. Afterwards, the non-adherent cells were washed-out with sterile PBS. The adherent Raw 264.7 cells were infected with metacyclic promastigotes $\left(4 \times 10^{5}\right.$ cells $)$ at an infection ratio of 1:10 macrophage: parasites and incubated for $24 \mathrm{~h}$ at $37^{\circ} \mathrm{C}$ under $5 \% \mathrm{CO}_{2}$ in order to allow infection of macrophages by metacyclic promastigotes. Thereafter, the overlying medium was removed, and the monolayer cells with internalized amastigotes were carefully washed four times with PBS to remove free parasites. Freshly prepared M199 medium containing 10\% FBS and the test extracts were added in triplicate to the infected cells at serially diluted concentrations and incubated for $48 \mathrm{~h}$ at $37{ }^{\circ} \mathrm{C}$ under $5 \% \mathrm{CO}_{2}$. After incubation, $0.05 \%$ Sodium dodecyl sulfate (SDS) was added in each well for $30 \mathrm{~s}$ for controlled lysis followed by M199 with $10 \%$ FBS as macrophage lysis stopper. Resazurin reagent $(250 \mu \mathrm{g} / \mathrm{mL})$ was thereafter added in each well and the plates were incubated for $24 \mathrm{~h}$ followed by fluorescence recording at $\lambda$ excitation $=530 \mathrm{~nm}$ and $\lambda$ emission $=590$ nm using a Tecan Infinite M200 microplate reader (Tecan). Inhibition percentages were calculated using Microsoft Excel Software and median inhibitory concentration $\left(\mathrm{IC}_{50}\right)$ obtained from dose-response curves using GraphPad Prism 5.0. Software.

\section{Cytotoxicity assay}

The cytotoxicity profile of extracts, fractions and compounds was assessed using the Alamar blue assay [24] against Raw 264.7 cells duly cultivated in complete Dulbecco's Modified Eagle's Medium (DMEM) containing $13.5 \mathrm{~g} / \mathrm{L}$ DMEM (Sigma Aldrich), 10\% fetal Bovine Serum (Sigma Aldrich), 0.2\% sodium bicarbonate (w/v) (Sigma, Darmstadt, Germany) and $50 \mu \mathrm{g} / \mathrm{mL}$ gentamycin (Sigma Aldrich). Globally, macrophages were seeded into 96-wells cell-culture flat-bottomed plates at a density of $10^{4}$ cells in final volume of $100 \mu \mathrm{L}$ of complete medium/ well and incubated for $24 \mathrm{~h}$ at $37^{\circ} \mathrm{C}, 5 \% \mathrm{CO}_{2}, 70 \% \mathrm{RH}$ in a ICO 105 memmert incubator (memmert, Schwabach, Germany) to allow cell adhesion. Ten $\mu \mathrm{L}$ of each serially diluted test sample were added in triplicate wells and assay plates were then incubated for $48 \mathrm{~h}$ in the same experimental conditions. Growth control consisted of $0.1 \% \mathrm{DMSO}(100 \%$ growth) and positive control of podophyllotoxin (Sigma, Darmstadt, Germany) at $20 \mu \mathrm{M}$. Cell proliferation was checked by adding $10 \mu \mathrm{L}$ of a stock solution of resazurin $(0.15 \mathrm{mg} / \mathrm{mL}$ in sterile PBS) to each well followed by plates incubation during $4 \mathrm{~h}$. Fluorescence was then read on a Tecan Infinite M200 fluorescence multi-well plate reader at an excitation/ emission of 530/590 nm. Results were expressed as 50\% cytotoxic concentrations $\left(\mathrm{CC}_{50}\right)$. Selectivity indices $\left(\mathrm{CC}_{50} / \mathrm{IC}_{50}\right.$, defining the balance between cytotoxicity and antileishmanial activity) were calculated for each test substance.

\section{Concentration/time inhibition kinetics of the most active fraction}

The growth inhibitory effect of the most active fraction against $L$. donovani promastigotes was examined by culturing parasites $\left(4 \times 10^{5}\right.$ cells $\left./ \mathrm{ml}\right)$ in freshly prepared complete M199 medium in the presence and absence of varying concentrations of the hexane fraction $\left(1 / 2 \mathrm{IC}_{50}\right.$, $\left.\mathrm{IC}_{50}, 2 \mathrm{x} \mathrm{IC}_{50}, 4 \mathrm{x} \mathrm{IC}_{50}\right)$, using amphotericin $\mathrm{B}$ as positive control $\left(1 / 2 \mathrm{IC}_{50}, \mathrm{IC}_{50}, 2 \mathrm{x} \mathrm{IC}_{50}, 4 \mathrm{x} \mathrm{IC}_{50}\right)$ for $120 \mathrm{~h}$. The number of viable parasites was determined after every $24 \mathrm{~h}$ over $120 \mathrm{~h}$ by staining with trypan blue. Quantification of viable parasites was achieved by counting the parasites with clear cytoplasm (non-stained) using a Neubauer hemocytometer with cover slips. Three independent experiments were performed for each sample.

\section{Data analysis}

All the activity data represent mean \pm standard deviation (SD) from three independent experiments. Microsoft Excel Software was used to calculate the percentage of inhibition. The $\mathrm{IC}_{50}$ and $\mathrm{CC}_{50}$ values were determined using GraphPad Prism 5.0 Software with data fitted by non-linear regression.

\section{Statistical analysis}

Data were expressed as mean \pm SEM (standard error of mean). Statistical analysis was performed by one-way ANOVA (analysis of variance) followed by the Bonferroni post-test using GraphPad 7 software. Difference was considered as significant at $p<0.05$.

\section{Results \\ Phytochemical analysis data}

The crude extract, the hexane and dichloromethane soluble fractions of the trunk of $D$. gracilescens were analyzed by UPLC coupled to both diode array and mass spectrometry detectors. The latter was used with an electrospray ionization (ESI) source in positive ion mode. A representative base peak chromatogram and all ions MS (Fig. 1) indicating that the used UPLC conditions allowed a good separation of a large percentage of compounds. The compounds were recognizable from 
their characteristic UV spectra, which were identified based on the UPLC-DAD-HRESI-MS data and subsequent confirmation by comparison with literature data. The chromatographic profile and spectroscopic data are presented in Table 1 and Fig. 2 below.

\section{Biological activities data}

\section{Antileishmanial activity of plant samples}

The inhibitory potential of $D$. gracilescens extracts against $L$. donovani promastigotes was measured by direct counting of live promastigotes after parasite exposure to various concentrations of extract. The $\mathrm{IC}_{50}$ values of the different crude extracts are shown in Table 2 below.

The results shown in Table 2 indicate that only the extract from the trunk of $D$. grascilisens exerted antileishmanial activity with an $\mathrm{IC}_{50}$ value of $5.84 \mu \mathrm{g} / \mathrm{mL}$. The other extracts were non-active up to $100 \mu \mathrm{g} / \mathrm{mL}$. The trunk extract was therefore progressed for bio-guided investigation.

\section{Bio-guided fractionation of the trunk extract of $D$. grascilisens}

Fractionation of the trunk extract was performed by liquid-liquid partition to afford four (04) main fractions that were tested for activity against the promastigotes and amastigotes forms of L. donovani (Table 3).

Results from Table 3 indicate that bio-guided fractionation of the crude trunk extract $\left(\mathrm{IC}_{50}=5.84 \mu \mathrm{g} / \mathrm{mL}\right.$ ) has resulted in more potent fractions, with increase in activity in the range of 7.4-2-fold against $L$. donovani promastigotes $\left(\mathrm{IC}_{50}=0.79-2.36 \mu \mathrm{g} / \mathrm{mL}\right)$. The hexane fraction showed the highest potency $\left(\mathrm{IC}_{50}=0.79 \mu \mathrm{g} / \mathrm{mL}\right)$, followed respectively by the n-butanol $\left(\mathrm{IC}_{50}=1.11 \mu \mathrm{g} /\right.$ $\mathrm{mL})$, dichloromethane $\left(\mathrm{IC}_{50}=1.63 \mu \mathrm{g} / \mathrm{mL}\right)$ and ethyl acetate $\left(\mathrm{IC}_{50}=2.36 \mu \mathrm{g} / \mathrm{mL}\right)$ fractions. The water residue showed no activity up to $100 \mu \mathrm{g} / \mathrm{mL}$. Activity data against $L$. donovani amastigotes indicated decreased potency of the crude trunk extract $\left(\mathrm{IC}_{50}=35.69 \mu \mathrm{g} / \mathrm{mL}\right)$ and the hexane fraction $\left(\mathrm{IC}_{50}=8.06 \mu \mathrm{g} / \mathrm{mL}\right)$. Overall, the extract and fractions showed greater selectivity against L. donovani promastigotes $(18<\mathrm{SI}<127)$ than against the amastigotes $(2.8<\mathrm{SI}<12.4)$. The hexane fraction exhibited the highest selectivity against $L$. donovani promastigotes (SI > 126.7) and amastigotes (SI > 12.4).

Further fractionation of fraction A led to the isolation of lupeol (1) and a mixture of sterols (4). Fraction B led to betulin (2) and betulinic acid (3) and fraction D led to $\beta$-sitosterol glucoside (6) and 1-deoxyinositol (7) as shown in Fig. 3 below. The structures of these compounds were elucidated on the basis of spectroscopic analyses, including $1 \mathrm{D}$ and 2D NMR, and HR-ESI-MS and by comparison of their data with those reported in the literature (see supplementary information). These compounds were also tested for activity against the promastigote and amastigote forms of $L$. donovani. The results achieved are presented in Table 4.

Globally, the isolated compounds exhibited moderate inhibition of $L$. donovani promastigotes $\left(\mathrm{IC}_{50}\right.$ : 13.69$241.71 \mu \mathrm{M})$ and amastigotes $(17.83-120 \mu \mathrm{M})$. Of note, the activity of 1-deoxyinositol $\left(\mathrm{IC}_{50}\right.$ of $241.71 \mu \mathrm{M}$ and $120 \mu \mathrm{M}$ against promastigotes and amastigotes respectively) is being reported here for the first time.

\section{Kinetics of parasite killing as a relation to time and inhibitor concentration}

The following graphs below (Fig. 4) show the time kill kinetic of the most active (Hexane) fraction (A), compared to the positive control, amphotericin B (B).

The ability of the hexane fraction to fast-kill L. donovani promastigotes was assessed at different concentrations points $\left(0.5 \mathrm{x} \quad \mathrm{IC}_{50}, \mathrm{IC}_{50}, 2 \mathrm{x} \quad \mathrm{IC}_{50}\right.$ and $\left.4 \mathrm{x} \quad \mathrm{IC}_{50}\right)$ relative to untreated parasites culture over a period of $120 \mathrm{~h}$. The results showed that treatment with increasing concentrations of the hexane fraction and amphotericin $B$ resulted in a significant reduction in promastigote replication after $24 \mathrm{~h}$ (Fig. 4). In the meantime, an exponential growth was observed in untreated parasite culture.

Table 1 FT-MS product ions of detected compounds in the trunk extract of D. gracilescens

\begin{tabular}{|c|c|c|c|c|c|c|}
\hline \multirow[t]{2}{*}{$\mathrm{N}^{\circ}$} & \multirow{2}{*}{$\begin{array}{l}\text { RT } \\
(\min )\end{array}$} & \multicolumn{2}{|l|}{$[\mathrm{M}+\mathrm{H}]^{+}$} & \multirow{2}{*}{$\begin{array}{l}\text { UV, } \\
\lambda_{\max } \\
(\mathrm{nm})\end{array}$} & \multirow{2}{*}{$\begin{array}{l}\text { molecular } \\
\text { formula }\end{array}$} & \multirow{2}{*}{$\begin{array}{l}\text { Name of } \\
\text { compound }\end{array}$} \\
\hline & & Exp. & Calcd. & & & \\
\hline 1 & 7.19 & 663.4740 & 663.4772 & 222 & $\mathrm{C}_{46} \mathrm{H}_{62} \mathrm{O}_{3}$ & Chlorobiumquinone \\
\hline 2 & 6.99 & 431.3689 & 431.3672 & 222 & $\mathrm{C}_{32} \mathrm{H}_{46}$ & $\mathrm{NI}$ \\
\hline 3 & 6.82 & 483.3621 & 483.3621 & 450 & $\mathrm{C}_{30} \mathrm{H}_{46} \mathrm{O}$ & $\mathrm{NI}$ \\
\hline 4 & 6.77 & 427.3946 & 427.3946 & 222 & $\mathrm{C}_{30} \mathrm{H}_{50} \mathrm{O}$ & Lupeol \\
\hline 5 & 6.65 & 469.3465 & 469.3421 & 222 & $\mathrm{C}_{32} \mathrm{H}_{46} \mathrm{O}$ & $\mathrm{NI}$ \\
\hline 6 & 6.57 & 479.3887 & 479.3884 & 222 & $\mathrm{C}_{33} \mathrm{H}_{50} \mathrm{O}_{2}$ & $\mathrm{NI}$ \\
\hline 7 & 6.21 & 391.3003 & 391.2995 & 222 & $\mathrm{C}_{28} \mathrm{H}_{38} \mathrm{O}$ & $\mathrm{NI}$ \\
\hline 8 & 5.13 & 579.3116 & 579.3105 & 218 & $\mathrm{C}_{38} \mathrm{H}_{42} \mathrm{O}_{5}$ & $\mathrm{NI}$ \\
\hline
\end{tabular}




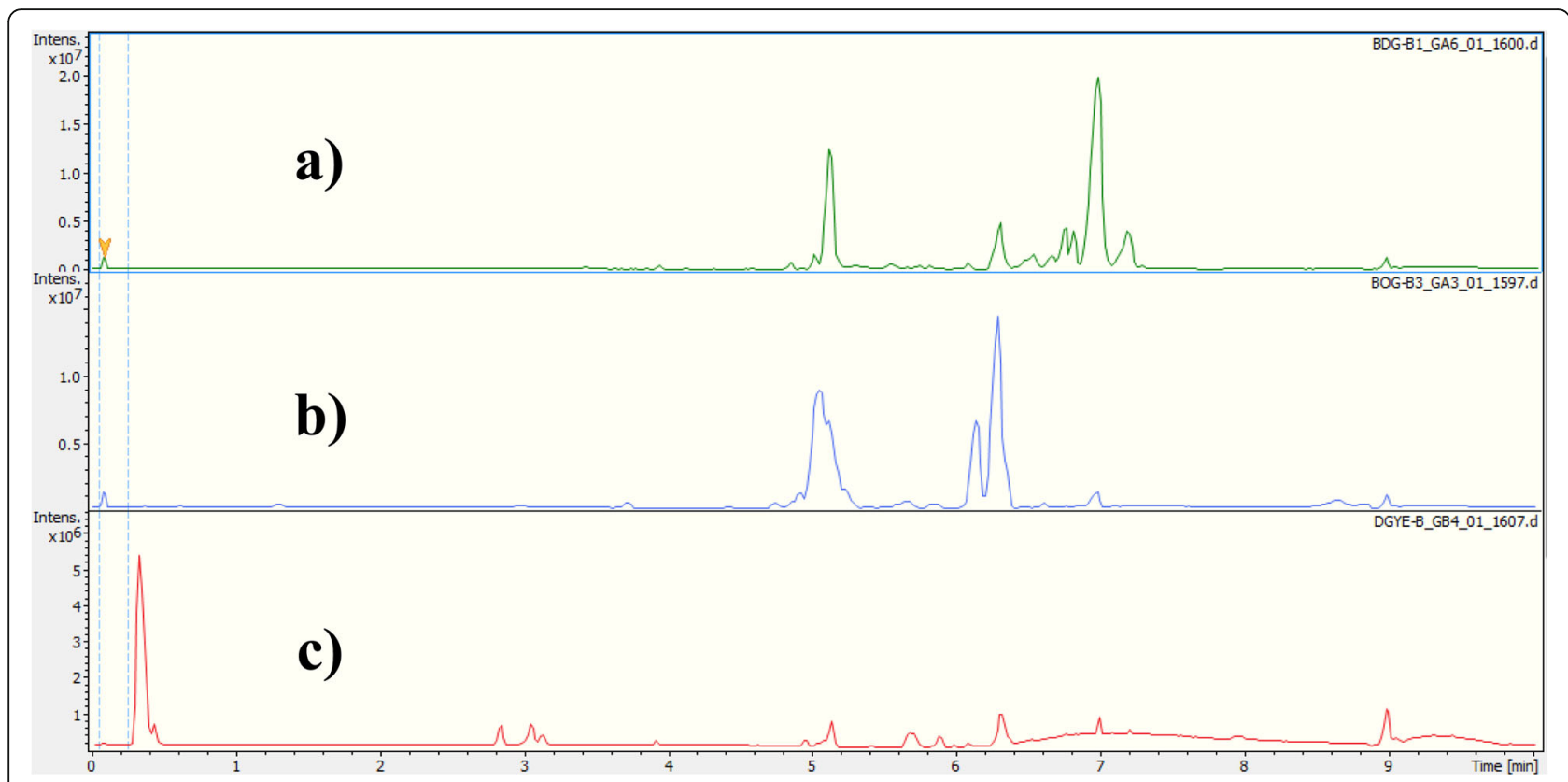

Fig. 2 HPLC profiles of the crude extract and fractions from the trunk of D. gracilescens (TIC: m/z 150-1000). a crude extract; b Dichloromethane fraction; c Hexane fraction

At all tested concentrations of hexane fraction and amphotericin $\mathrm{B}$, a regular reduction of the viability of treated parasite cultures was observed up to $120 \mathrm{~h}$, with however no evidence of cidal effect.

\section{Discussion}

The investigation of extracts from $D$. grascilesens for antileishmanial activity identified the hydroethanolic trunk extract as a promising starting point for bioguided study. This is the first report describing the antileishmanial activity of extracts from D. grascilesens. However, extracts from other Diospyros spp. have been previously investigated in this direction. Of note, Lenta et al. [25] demonstrated the capacity of the dichloromethane-methanol (1:1) extract of $D$. canaliculata (De Wild.) to inhibit the growth of axenic amastigotes of $L$. donovani. On another hand, Dhar et al. [26] reported that ethanolic extracts of $D$. montana (Roxb) and D. peregrina ((Gaertn.) Gürke) possess antiprotozoal activity against Entamoeba histolytica, antiviral activity against Ranikhet disease virus and hypoglycemic activities in albino rats. Rocío et al. [27] also demonstrated the in vitro antimycobacterial potency of the stem bark extract from $D$. anisandra (S.F. Blake) against a resistant strain of M. tuberculosis. In other studies, Hazra et al. [28] demonstrated the anti-tumour activity of bark extract from D. ferrea ((Willd.) Bakh). Asolkar et al. [29] showed the antibacterial activity of leaf and seed extracts from D. montana and Satish and Sunil [30] demonstrated the anti-diabetic and antioxidant potential of the ethanolic bark extract of $D$. malabarica.

Based on the criteria set for antileishmanial activity of plant extracts by Camacho et al. [31], the promising hydroethanolic trunk extract of $D$. grascilesens was further fractionated yielding the hexanic fraction as the more active and selective against the extracellular and the intracellular forms of $L$. donovani parasite. Further fractionation of this fraction led to six (6) compounds

Table 2 Anti-leishmanial activity of D. gracilescens crude extracts against promastigotes of $L$. donovani

\begin{tabular}{llll}
\hline Plant & Part & Solvent & $\begin{array}{l}\text { Promastigote of } \text { L. donovani (MHOM/SD/62/1S) } \\
\mathbf{I C}_{\mathbf{5 0}} \pm \mathbf{S D}(\boldsymbol{\mu g} / \mathbf{m l})\end{array}$ \\
\hline D. grascilisens & Root & $\mathrm{H}_{2} \mathrm{O}: \mathrm{EtOH}$ & $>100$ \\
& Stem bark & $\mathrm{H}_{2} \mathrm{O}: \mathrm{EtOH}$ & $>100$ \\
& Leaf & $\mathrm{H}_{2} \mathrm{O}: \mathrm{EtOH}$ & $>100$ \\
& Trunk & $\mathrm{H}_{2} \mathrm{O}: \mathrm{EtOH}$ & $5.84 \pm 0.20$ \\
Positive control & & $0.34 \pm 0.22$ \\
\hline
\end{tabular}

Activity data are expressed as mean \pm Standard deviation (SD) from triplicate experiments; $I_{50}$ : $50 \%$ Inhibitory Concentration 
Table 3 Anti-leishmanial activity and selectivity Indexes of fractions from the trunk crude extract against promastigotes and amastigotes of L. donovani

\begin{tabular}{|c|c|c|c|c|c|}
\hline Extract/ fraction & $\begin{array}{l}\mathrm{IC}_{50} \text { (Promastigotes) }(\mu \mathrm{g} / \\
\mathrm{ml} \pm \mathrm{SD})\end{array}$ & $\begin{array}{l}\mathrm{IC}_{50} \text { (Amastigotes) }(\mu \mathrm{g} / \\
\mathrm{ml}) \pm \mathrm{SD}\end{array}$ & $\begin{array}{l}\text { Raw267.4 CC } 50(\mu \mathrm{g} / \\
\mathrm{ml} \pm \mathrm{SD})\end{array}$ & $\begin{array}{l}\text { SI } \\
\text { (Promastigotes) }\end{array}$ & $\begin{array}{l}\text { SI } \\
\text { (Amastigotes) }\end{array}$ \\
\hline Trunk crude extract & $5.84 \pm 0.20^{f}$ & $35.69 \pm 0.26^{f}$ & $>100$ & $>18.56$ & $>2.80$ \\
\hline Hexane fraction (A) & $0.79 \pm 0.09^{b}$ & $8.06 \pm 0.39^{b}$ & $>100$ & $>126.74$ & $>12.40$ \\
\hline $\begin{array}{l}\text { Dichloromethane } \\
\text { fraction (B) }\end{array}$ & $1.63 \pm 0.11^{d}$ & $10.97 \pm 0.11^{c}$ & $>100$ & $>61.16$ & $>9.11$ \\
\hline Ethyl-acetate fraction (C) & $2.36 \pm 0.06^{\mathrm{e}}$ & $16.05 \pm 0.12^{d}$ & $>100$ & $>42.30$ & $>6.23$ \\
\hline n-butanol fraction (D) & $1.11 \pm 0.10^{c}$ & $22.08 \pm 0.09^{e}$ & $>100$ & $>89.60$ & $>4.53$ \\
\hline Water residue (E) & $>100$ & - & - & - & - \\
\hline Positive control & $0.34 \pm 0.22^{\mathrm{a}}$ & $0.12 \pm 0.11^{\mathrm{a}}$ & / & / & / \\
\hline
\end{tabular}

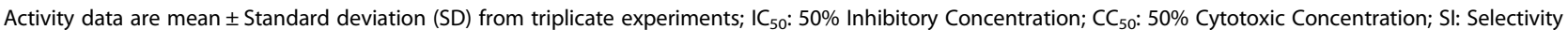
Index. Along each column, $I_{50}$ values with the same letter superscripts are not significantly different, Bonferroni test $(p>0.05)$

identified as lupeol, betulin, betulinic acid, mixture of sterols, $\beta$-sitosterol glucoside and 1-deoxyinositol. Among these compounds, betulinic acid showed the most potent activity and selectivity against both promastigote and amastigote forms of $L$. donovani. There are few studies in the literature reporting the activity of betulin and betulinic acid and derivatives against Leishmania parasites. Indeed, similarly to our findings, Sousa et al. [32] have reported moderate antileishmanial activity $(23-55 \mu \mathrm{M})$ of semisynthetic lupane triterpenoids, betulin and betulinic acid when tested alone, and their synergistic effects with miltefosine, an alkylphosphocholine drug with demonstrated activity against various parasite species (including Leishmania infantum parasites and amoeba) and cancer cells as well as some pathogenic bacteria and fungi [33]. Alakurtti et al. [34] also determined the activity of heterocyclic betulin derivatives on $L$. donovani amastigotes and the in vitro activity of betulin and betulinic acid derivatives against $L$. donovani amastigotes and promastigotes of $L$. amazonensis. Dominguez et al. [35] also reported the activity of betulinic acid acetate and betulinic acid methyl ester against promastigotes of $L$. amazonensis.

Betulinic acid has been already reported in the literature to possess a wide range of biological and medicinal properties, including anti-human immunodeficiency virus (HIV), antibacterial, antimalarial, antiinflammatory, anthelmintic, antinociceptive, anti-herpes simplex viruses-1 (HSV-1), immune-modulatory, antiangiogenic, and anticancer activities [36, 37]. The activity of betulinic acid and its derivatives against the erythrocytic stage of the chloroquine-sensitive 3D7 Plasmodium falciparum strain was previously reported, as well as moderate antileishmanial activity on different Leishmania spp. [34, 38, 39]. Cassio et al. [40] also showed that the semi-synthetic derivatives of betulinic acid were able to prevent the parasite development and invasion into host cells, that are crucial events for Trypanosoma cruzi infection establishment, with potency similar to benznidazole.

In this study, lupeol was found to be active against promastigotes and moderately active against amastigotes

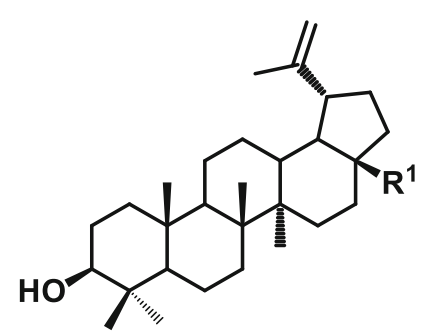<smiles>[R20]C1CCC2(C)C(=CCC3C4CCC([C@H](C)/C=C/[C@H](CC)C(C)C)C4(C)CC[C@H]32)C1</smiles><smiles>OC1CC(O)C(O)C(O)C1O</smiles>

$7=1$-Deoxyinositol
$1 \mathrm{R}^{1}=\mathrm{Me}$
lupeol
$4 \mathrm{R}^{2}=\mathrm{H}$
$\beta$-sitosterol
$2 \mathrm{R}^{1}=-\mathrm{CH}_{2} \mathrm{OH}$ betulin
$5 \mathrm{R}^{2}=\mathrm{H}, \Delta^{22}$ stigmasterol
$3 \mathrm{R}^{1}=\mathrm{COOH}$ betulinic acid
$6 \mathrm{R}^{2}=\mathrm{GlC} \quad \beta$-sitosterol 3-O-D-glucopyranoside

Fig. 3 Isolated compounds from D. gracilescens. Structures of the isolated compounds were elucidated by means of physical and spectroscopic methods 
Table 4 Anti-leishmanial activity and selectivity indexes of isolated compounds against L. donovani promastigotes and amastigotes

\begin{tabular}{|c|c|c|c|c|c|}
\hline Compound & $\begin{array}{l}\mathrm{IC}_{50} \\
\text { (Promastigotes) }(\mu \mathrm{M} \pm \mathrm{SD})\end{array}$ & $\begin{array}{l}\mathrm{I} C_{50} \\
\text { (Amastigotes) } \\
(\mu \mathrm{M} \pm \mathrm{SD})\end{array}$ & $\begin{array}{l}\text { Raw267.4 } C_{50} \\
(\mu \mathrm{M} \pm \mathrm{SD})\end{array}$ & SI (Promastigotes) & SI (Amastigotes) \\
\hline Lupeol (1) from fraction A & $23.22 \pm 0.08$ & $46.66 \pm 0.65$ & $19.28 \pm 0.3$ & 0.82 & 0.41 \\
\hline Betulin (2) from fraction B & NT & NT & ND & ND & ND \\
\hline Betulinic acid (3) from fraction B & $13.69 \pm 0.07$ & $18.46 \pm 0.01$ & $82.39 \pm 0.09$ & 6.02 & 4.46 \\
\hline Mixture of sterols (4) from fraction A & $46.83 \pm 0.20$ & $17.83 \pm 0.17$ & $18.26 \pm 0.18$ & 0.39 & 1.02 \\
\hline$\beta$-sitosterol glucoside (6) from fraction D & $49.34 \pm 0.12$ & $32 \pm 0.22$ & $28.60 \pm 0.07$ & 0.58 & 0.89 \\
\hline 1-deoxyinositol (7) from fraction D & $241.71 \pm 0.16$ & $120 \pm 0.18$ & $>1218 \pm 0.13$ & $>5.04$ & $>10.15$ \\
\hline Amphotericin B & $0.37 \pm 0.22$ & $0.13 \pm 0.11$ & & / & / \\
\hline
\end{tabular}

Activity data are expressed as mean \pm Standard deviation (SD) from triplicate experiments; IC 50 : 50\% Inhibitory Concentration, ND: Non-Determined; NT: NonTested (Betulin not tested due to insufficient quantity)

of $L$. donovani, corroborating the previous findings. Indeed, the antileishmanial activity of lupeol against both promastigotes and amastigotes of $L$. donovani has been demonstrated in the literature [41]. Other previous studies indicated that lupeol isolated from aerial parts of Vernonia scorpioides displayed a weak antileishmanial activity [42, 43]. Also, studies have highlighted the activity of lupeol from the latex of E. resinifera and E. officinarum against promastigote of L. infantum [44]. Other studies attempting to establish the mechanism of action of lupeol were conducted by Ramos et al. [45] and showed that this compound mediates an increased cytoplasmic membrane depolarization which may promote enhanced cell membrane damage. They also suggested that the leishmanicidal activity could lead to disruption of the cytoplasmic membrane of $L$. donovani promastigotes as evidenced by DISC3 mediated fluorometric analysis. Whereas lupeol might mediate reduction in intracellular parasitic load was found to be executed through the induction of pro-inflammatory cytokine response and generation of Nitrite Oxide (NO) in $L$. donovani infected macrophages [41].

Betulinic acid and lupeol that showed the most potent activity in this study belong to the class of terpenoids. In fact, a number of terpenes are reputed to possess antileishmanial activity. Different authors suggested that the antileishmanial activity of these compounds could be related to the inhibition of proteins and nucleic acids synthesis or of a membrane-associated calcium-dependent ATPase pump [43, 46]. Indeed, previous studies have suggested that lipophilic compounds, such as triterpenes, act by a peculiar mechanism. These compounds can pass easily through the cytoplasmic membranes, affecting structures of their different layers of polysaccharides, fatty acids, and phospholipids, thus making them permeable [47]. Once they cross the membrane, the coagulation of cytoplasm can occur. These events are able to promote the interruption of specific metabolic pathways of lipids and proteins [48], interference in cell division $[49,50]$, or stimulate the depolarization of the mitochondrial membranes, which can lead the cell to trigger necrosis or apoptosis mechanisms [51].

Among the isolated compounds, 1-deoxyinositol exerted a promising activity against both promastigote and amastigote forms of $L$. donovani. This compound was previously detected by GC-MS in a moderately active (with $\mathrm{IC}_{50}$ value of $126.4 \mu \mathrm{g} / \mathrm{mL}$ ) methanolic extract from the aerial part of Scutellaria havanensis against $L$.
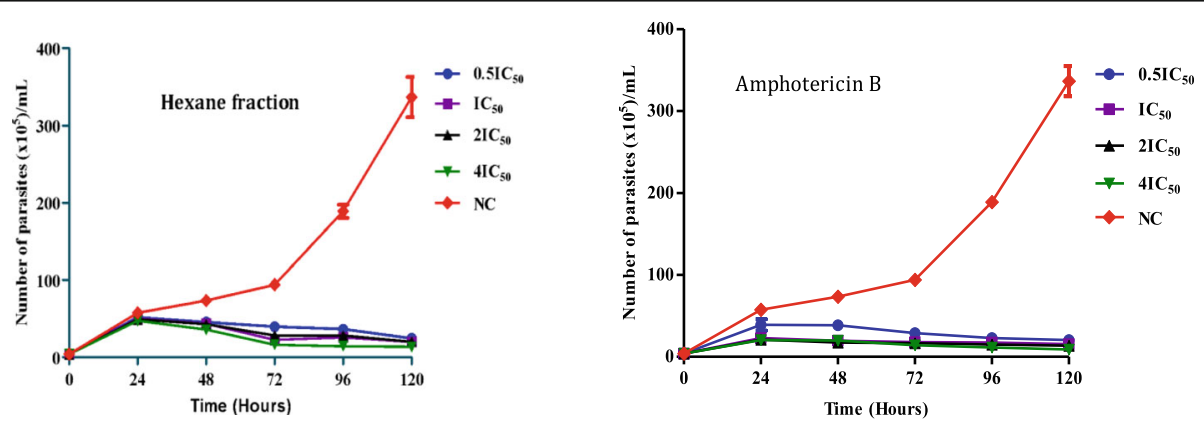

Fig. 4 Kill kinetics of L. donovani promastigotes in relation to drug concentration and time. Cells were treated with different concentrations of (a) hexane fraction and (b) amphotericin B. The growth kinetic curves were plotted as number of viable parasites vs time with data collected every 24 h over a period of $120 \mathrm{~h}$; NC = Negative control; Each data point represents mean \pm SD from three experiments 
amazonensis promastigotes [52]. The antileishmanial activity of 1-deoxyinositol adds to the novelty of this work given that, to the extent of our knowledge, no previous report has been published on the antileishmanial activity of this compound. More interestingly, 1-deoxyinositol showed the highest selectivity against $L$. donovani promastigotes $(\mathrm{SI}>5.04)$ as well as acceptable preference for amastigotes (SI > 10.15).

Overall, this study has indicated that the hexane fraction was 12 to 49 -fold and 1.8 to 2.4-fold more active than the derived lupeol and mixture of sterols against the promastigote and amastigote forms of $L$. donovani respectively. Also, selectivity indexes greater than 152 and 11 for promastigotes and amastigotes respectively were obtained compared to the derived components. The activity profile of the hexane fraction portents a very probable synergistic interaction between its nonpolar components to increase activity and selectivity (safety profile). The implication of these findings is of high significance in the use of $D$. grascilesens plant in traditional medicine to treat neglected tropical diseases (NTDs).

\section{Conclusion}

This study reports the first detailed investigation aiming at determining the antileishmanial activity of natural products from $D$. gracilescens using a bio-guided approach. The hydroethanolic extract of the trunk showed promising profile, $\left(\mathrm{IC}_{50}=5.84 \mu \mathrm{g} / \mathrm{mL}\right)$ and its bio-guided fractionation led to the most potent hexane fraction $\left(\mathrm{IC}_{50}=0.79 \mu \mathrm{g} / \mathrm{mL}\right)$. Further fractionation of this fraction led to six compounds that also exhibited antileishmanial potency. The promising hexane fraction and derived active compounds represent potential raw materials for detail-oriented drug discovery against visceral leishmaniasis that exacts a very heavy toll to poor patients in remote endemic settings in Africa and elsewhere. Among the isolated compounds, 1-deoxyinositol has shown acceptable profile for further structureactivity-relationship studies in drug discovery program to unveil hits or leads adhering to the criteria defined earlier against visceral leishmaniasis. Of particular note is the activity profile of the hexane fraction that exerted the greatest potency and selectivity. It is a promising candidate for the development of a phytodrug against leishmaniasis.

\footnotetext{
Abbreviations

$\mathrm{CC}_{50}$ : 50\% cytotoxic concentration; D.: Diospyros; DMEM: Dulbecco's Modified Eagle's Medium; DMSO: Dimethylsulfoxide; ESI: Electrospray lonization; FBS: Fetal Bovine Serum; FT-MS: Fourier Transform Mass Spectrometry; HIFBS: Heat-Inactivated fetal Bovine Serum; HIV: Human Immunodeficiency Virus; HPLC: High Performance Liquid Chromatography; HRESI: High Resolution Electrospray Ionization; HSV-1: Herpes simplex viruses-1; IC 50 : 50\% inhibitory concentration; L.: Leishmania; M199: Medium 199; M. tuberculosis: Mycobacterium tuberculosis; MS: Mass Spectrometry;
}

NC: Negative control; NI: Not Identified; NO: Nitrite Oxide; NT: Non-tested; NTD: Neglected Tropical Disease; PBS: Phosphate Buffer Solution; SD: Standard deviation; SDS: Sodium Dodecyl sulfate; SI: Selectivity Index; T. cruzi: Trypanosoma cruzi; TIC: Total Ion Chromatogram; UPLC: Ultra Performance Liquid Chromatography; VL: Visceral Leishmaniasis; WHO: World Health Organization

\section{Supplementary Information}

The online version contains supplementary material available at https://doi. org/10.1186/s12906-021-03279-1.

\section{Additional file 1}

\section{Acknowledgments}

The authors are thankful to Bei Resources for providing leishmania donovani 1S (MHOM/SD/62/1S) strain; the Noguchi Memorial Institute for Medical Research, University of Ghana for providing the Raw 264.7 cells. The authors wish also to express their heartfelt gratitude to The World Academy of Science (TWAS) (grant N ${ }^{\circ} 18-178$ RG/CHE/AF/AC_G-FR3240303654), and the Alexander von Humboldt Foundation for the equipment support to SKF.

\section{Authors' contributions}

FFB and SFK designed the study. CANN, CNW, DD and BMTT carried out studies and drafted the manuscript. LRTY, PVTF supervised the biological experiments. MNP collected the plant material. JBJ performed the acquisition of LC-MS data. FFB, SKF, BLN and NS revised the manuscript. All the authors approved the final version of the manuscript.

\section{Funding}

Consumables and equipment for this study were provided by the YaoundéBielefeld Bilateral Graduate School of Natural Products with Anti-parasitic and Anti-bacterial activities (YaBiNaPA), project Nº57316173 funded by the German Academic Exchange Service (DAAD), the Federal Republic of Germany.

Availability of data and materials

All data generated or analyzed during this study are included in this published article and its Additional files.

\section{Declarations}

Ethics approval and consent to participate

Not applicable.

Consent for publication

Not applicable.

\section{Competing interests}

The authors declare that they have no competing interests.

\section{Author details}

${ }^{1}$ Antimicrobial and Biocontrol Agents Unit, Laboratory for Phytobiochemistry and Medicinal Plants Studies, Department of Biochemistry, Faculty of science University of Yaounde I, P. O Box 812, Yaounde, Cameroon. ${ }^{2}$ Department of Chemistry, Higher Teacher Training College, University of Yaounde I, P. O. Box 47, Yaounde, Cameroon. ${ }^{3}$ Institute of Medical Research and Medicinal Plants Studies (IMPM), Ministry of Scientific Research and Innovation, P.O. Box 6133, Yaounde, Cameroon. ${ }^{4}$ Department of Biochemistry, Faculty of science University of Bamenda, Bambili, P. O Box. 39, Bamenda, Cameroon.

${ }^{5}$ Laboratory of Animal Physiology, Department of Animal Biology and Physiology, Faculty of Science, University of Yaounde I, P. O Box 812, Yaounde, Cameroon. ${ }^{6}$ Organic and Bioorganic Chemistry, Faculty of Chemistry, University of Bielefeld, D-33501 Bielefeld, Germany. ${ }^{7}$ Chemical Engineering and Mineral Industries School, University of Ngaoundere, P. O. Box 454, Ngaoundere, Cameroon. 
Received: 6 July 2020 Accepted: 17 March 2021 Published online: 31 March 2021

\section{References}

1. Akhoundi M, Kuhls K, Cannet A, Votypka J, Marty P, Delaunay P, et al. Historical overview of the classification, evolution, and dispersion of Leishmania parasites and sandflies. PLoS Negl Tropl Dis. 2016;10(3): e0004349. https://doi.org/10.1371/journal.pntd.0004349.

2. Torres-Guerrero E, Quintanilla-Cedillo MR, Ruiz-Esmenjaud J, Arenas R. Leishmaniasis: a review. F1000Res. 2017;6:750.

3. World Health Organization. Leishmaniasis. Fact sheet N³75. World Health Organization,Thailand.http://www.searo.who.int/thailand/factsheets/fs0013/ n/. 2014. (Accessed 16 June 2018).

4. WHO. Working to Overcome the Global Impact of Neglected Tropical Diseases: First WHO Report on Neglected Tropical Diseases. Geneva No.1: WHO; 2010.

5. Steverding D. The history of leishmaniasis. Parasit Vectors. 2017;10(1):82. https://doi.org/10.1186/s13071-017-2028-5.

6. Arevalo J, Ramirez L, Adaui V, Zimic M, Tulliano G, Miranda-Verástegui C, et al. Influence of Leishmania (Viannia) species on the response to antimonial treatment in patients with American tegumentary leishmaniasis. J Infect Dis. 2007:195(12):1846-51. https://doi.org/10.1086/518041.

7. Goto H, Lindoso JL. Current diagnosis and treatment of cutaneous and mucocutaneous leishmaniasis. Expert Rev Anti-Infect Ther. 2010;8(4):419-33. https://doi.org/10.1586/eri.10.19.

8. Croft SL, Coombs GH. Leishmaniasis; current chemotherapy and recent advances in the search for novel drugs. Trends Parasitol. 2003;19(11):502-8. https://doi.org/10.1016/j.pt.2003.09.008.

9. Berman JD, Badaro R, Thakur CP, Wasunna KM, Behbehani K, Davidson R, et al. Efficacy and safety of liposomal amphotericin B (AmBisome) for visceral leishmaniasis in endemic developing countries. B WHO. 1998;76(1): 25-32.

10. WHO. General guideline for methodologies on research and evaluation of traditional medicine. W.H.O /E.D.M. /T.R.M; 2000. p. 1. Pp 27

11. Kaushik V, Saini V, Pandurangan A, Khosa RL, Parcha V. A review of phytochemical and biological studies of Diospyros malabarica. Inter J Pharm Sci Lett. 2012:2:167-9.

12. Gafner F, Chapuis JC, Msonthi JD, Hosttemann K. Cytotoxic naphtoquinones, molluscidal saponins and flavonoids from Diospyros zombensis. Phytochem. 1987;26(9):2501-3. https://doi.org/10.1016/S0031-9422(00)83864-9.

13. Kerharo J, Bouquet A. La chasse en Côte d'Ivoire et en Haute-Volta. Acta Trop. 1949;6(3):193-220.

14. Mbi CN, Waterman PG. Sterols and naphthoquinones from Diospyros gracilescens. J Pharm Pharmacol. 1978;30(S1):86P. https://doi.org/10.1111/j.2 042-7158.1978.tb10793.x

15. Xie $K$, Huang $K$, Yang $R$, Yu H, Liu Z. Three liquid-phase extraction: a new approach for simultaneous enrichment and separation of $\mathrm{Cr}(\mathrm{III})$ and $\mathrm{Cr}(\mathrm{VI})$. Ind Eng Chem Res. 2011:50(22):12767-73. https://doi.org/10.1021/ie201816j.

16. Abdullahi SM, Musa AM, Abdullahi MI, Sule MI, Sani YM. Isolation of lupeol from the stem-bark of Lonchocarpus sericeus (Papilionaceae). J Biosci. 2013; 1(1):18-9.

17. Wouamba SCN, Happi GM, Lenta BN, Sewald N, Kouam SF. Vernoguinamide: A new ceramide and other compounds from the root of Vernonia guineensis Benth and their chemophenetic significance. Biochem Syst Ecol. 2020;88:103988.

18. Tijjani A, Ndukwe IG, Ayo RG. Isolation and characterization of lup-20 (29)ene-3, 28-diol (Betulin) from the stem-bark of Adenium obesum (Apocynaceae). Trop J Pharm Res. 2012;11(2):259-62.

19. SCN W, Happi GM, Nguiam Pouofo M, Tchamgoue J, Jouda JB, Longo F, et al. Antibacterial flavonoids and other compounds from the aerial parts of Vernonia guineensis Benth.(Asteraceae). Chem. Biodivers. 2020;17(9):e2000296.

20. Venkateswara RG, Sahoo MR, Madhavi MSL, Mukhopadhyay T. Phytoconstituents from the leaves and seeds of Manilkara zapota Linn. Der Pharm Lett. 2014:6:69-73.

21. Khanjani JS, Farazmand A, Amin M, Doroodgar A, Shirzadi M, Razavi M. Methanolic extract's activity of Artemisia absinthium, Vitex agnus-castus and Phytolaca americana against Leishmania major in vitro and in vivo. IAHS. 2015;2(2):69-74.

22. Siqueira-Neto $J$, Song $\mathrm{OR}$, Oh H, Sohn JH, Yang G, Nam J, et al. Antileishmanial high-throughput drug screening reveals drug candidates with new scaffolds. PLoS Negl Trop Dis. 2010;4(5):675.
23. Jain K, Sahu R, Walker A, Tekwani L. A parasite rescue and transformation assay for anti-leishmanial screening against intracellular Leishmania donovani amastigotes in THP1 human acute monocytic leukemia cell line. J Vis Exp. 2012;70:e4054.

24. Mosmann T. Rapid colorimetric assay for cellular growth and survival: application to proliferation and cytotoxicity assays. J Immunol Meth. 1983; 65(1-2):55-63. https://doi.org/10.1016/0022-1759(83)90303-4.

25. Lenta BN, Ngamgwe RF, Kamdem LM, Ngatchou J, Tantangmo F, Antheaume C, et al. Compounds from Diospyros canaliculata (Ebenaceae) and their Antiparasitic activities. Res J Pure Ap Chem. 2014;6(2):56-65.

26. Dhar ML, Dhar MM, Dhawan BN, Mehrotra BN, Ray C. Screening of Indian plants for biological activity. In J Exp Biol. 1968;6(4):232-47.

27. Rocío BA, Andrés UC, Carlos QN, Gonzalo CE, Mirbella C. A selective chemical method for the separation of quinones from the stem bark of Diospyros Anisandra. Int J Curr Pharm Res. 2013;5(4):13-7.

28. Hazra B, Sur P, Roy DK, Sur B, Banerjee A. Biological activity of diospyrin towards Ehrlich ascites carcinoma in Swiss a mice. Planta Med. 1984;50(4): 295-7. https://doi.org/10.1055/s-2007-969713.

29. Asolkar LV, Kakkar KK, Chakre OJ. Second supplement to glossary of Indian medicinal plants with active principles', CSIR, New Delhi; 1965. p. 271-9.

30. Satish AK, Sunil SJ. Screening of ethanolic extract of Diospyros malabarica Desr. Bark for anti-diabetic and antioxidant potential. J Pharm Educ Res. 2016:50(1):179-89.

31. Camacho MDR, Phillipson JD, Croft SL, Solis PN, Marshall SJ, Ghazanfar SA. Screening of plant extracts for antiprotozoal and cytotoxic activities. J Ethnopharmacol. 2003;89(2-3):185-91. https://doi.org/10.1016/S0378-8741(03 )00269-1.

32. Sousa MC, Varandas R, Santos RC, Santos-Rosa M, Alves V, Salvador JA. Antileishmanial activity of semisynthetic Lupane triterpenoids betulin and betulinic acid derivatives: synergistic effects with miltefosine. PLoS One. 2014;9(3):e89939. https://doi.org/10.1371/journal.pone.0089939.

33. Dorlo TPC, Balasegaram M, Beijnen JH, de Vries PJ. Miltefosine: a review of its pharmacology and therapeutic efficacy in the treatment of leishmaniasis. J Antimicrob Chemother. 2012;67(11):2576-97. https://doi.org/10.1093/jac/ dks275.

34. Alakurtti S, Heiska T, Kiriaziz A, Sacerdoti-Sierra N, Jaffe L, Yli-Kauhaluoma J. Synthesis and anti-leishmanial activity of heterocyclic betulin derivatives. Bioorg Med Chem. 2010;18(4):1573-82. https://doi.org/10.1016/j.bmc.2010. 01.003 .

35. Domínguez-Carmona DB, Escalante-Erosa F, García-Sosa K, Ruiz-Pinell G, Gutierrez-Yapu D, Chan-Bacab MJ, et al. Antiprotozoal activity of betulinic acid derivatives. Phytomedecine. 2010;17(5):379-82. https://doi.org/10.1016/ j.phymed.2009.08.002.

36. Yogeeswari $P$, Sriram D. Betulinic acid and its derivatives: a review on their biological properties. Curr Med Chem. 2005;12(6):657-66. https://doi.org/1 $0.2174 / 0929867053202214$

37. Gheorgheosu D, Duicu O, Dehelean C, Soica C, Muntean D. Betulinic acid as a potent and complex antitumor phytochemical: a minireview. Anti Cancer Agents Med Chem. 2014;14(7):936-45. https://doi.org/10.2174/1871520614 666140223192148

38. Chen Y, Li S, Sun F, Han H, Zhang X, Fan Y, et al. In vivo antimalarial activities of glycoalkaloids isolated from Solanaceae plants. Pharm Biol. 2010 48(9):1018-24. https://doi.org/10.3109/13880200903440211.

39. Innocente M, Silva N, Cruz N, Moraes S, Nakabashi M, Sonnet P, et al. Synthesis and antiplasmodial activity of betulinic acid and ursolic acid analogues. Molecules. 2012;17(10):12003-14. https://doi.org/10.3390/ molecules 171012003

40. Cassio SM, Jose MB, Lanfredi-Rangel A, Elisalva TG, Diogo M, Milena S. Antiparasitic evaluation of betulinic acid derivatives reveals effective and selective anti-Trypanosoma cruzi inhibitors. Exp Parasitol. 2016;166:108-15.

41. Das A, Junaid J, Manash D, Padmani S, Utpal C, Biswanath D, et al. Antileishmanial and immunomodulatory activity of lupeol a triterpene compound isolated from Sterculia villosa. Inter J Antimicrob Agents. 2017; 50(4):512-22. https://doi.org/10.1016/.ijantimicag.2017.04.022.

42. Fournet A, Angelo A, Munoz V, Roblot F, Hocquemiller R, Cave A. Biological and chemical studies of Pera benensis, a Bolivian plant used in folk medicine as a treatment of cutaneous leishmaniasis. J Ethnopharmacol. 1992;37(2): 159-64. https://doi.org/10.1016/0378-8741(92)90074-2.

43. Goijman G, Turrens F, Marini-Bettolo B, Stoppani O. Inhibition of growth and macromolecular biosynthesis in Trypanosoma cruzi by natural products. Effects Miconidine Tingenone. Medicina (Buenos Aires). 1984;44:361-70. 
44. Araujo C, Silva R, Silva M, Takahashi A, Sales-Junior A, Dessimoni-Pinto V, et al. Constituents from stem barks of Luehea ochrophylla Mart and evaluation of their antiparasitic, antimicrobial, and antioxidant activities. Nat Prod Res. 2016;31(16):1948-53. https://doi.org/10.1080/14786419.2016.12 66346.

45. Ramos H, Valdivieso E, Gamargo M, Dagger F, Cohen E. Amphotericin B kills unicellular leishmanias by forming aqueous pores permeable to small cations and anions. J Membr Biol. 1996;152(1):65-75. https://doi.org/10.1 007/s002329900086.

46. Mishina V, Krishna S, Haynes K, Meade C. Artemisinins inhibit Trypanosoma cruzi and Trypanosoma brucei rhodesiense in vitro growth. Antimicrob Agents Chemother. 2007;51(5):1852-4. https://doi.org/10.1128/AAC.01544-06.

47. DiPasqua GRBR, Hoskins MN, Edwards ED, Mauriello G. Membrane toxicity of antimicrobial compounds from essential oils. J Agric Food Chem. 2007; 55(12):4863-70.

48. Ultee KA, Alberda M, Hoekstra FA, Smid EJ. Adaptation of the food-borne pathogen Bacillus cereus to carvacrol. Arch Microbiol. 2000;174(4):233-8. https://doi.org/10.1007/s002030000199.

49. Fortes A, Almeida A, Mendonc A-Junior F, Freitas R, Soares-Sobrinho L, De La Roca Soares F. Anxiolytic properties of new chemical entity, $5 \mathrm{TIO1}$. Neurochem Res. 2013;38(4):726-31.

50. De Almeida M, Vilhena $V$, Barral A, Barral-Netto M. Leishmanial infection: analysis of its first steps. A review. Memorias do Instituto Oswaldo Cruz. 2003;98(7):861-70. https://doi.org/10.1590/S0074-02762003000700001.

51. Armstrong JS. Mitochondrial membrane permeabilization: the sine qua non for cell death. BioEssays. 2006;28(3):253-60. https://doi.org/10.1002/ bies.20370.

52. Fernandez-Calienes VA, Monzote FL, Sariego Rl, Marrero DD, Morales RCL, Mendiola MJ, et al. Antiprotozoal screening of the Cuban native plant Scutellaria havanensis. Pharm Biol. 2016;54(12):3197-202. https://doi.org/10.1 080/13880209.2016.1216130.

\section{Publisher's Note}

Springer Nature remains neutral with regard to jurisdictional claims in published maps and institutional affiliations.

Ready to submit your research? Choose BMC and benefit from:

- fast, convenient online submission

- thorough peer review by experienced researchers in your field

- rapid publication on acceptance

- support for research data, including large and complex data types

- gold Open Access which fosters wider collaboration and increased citations

- maximum visibility for your research: over $100 \mathrm{M}$ website views per year

At $\mathrm{BMC}$, research is always in progress.

Learn more biomedcentral.com/submissions 